\title{
Elementos para o Debate Acerca do Conceito de Turismo Rural
}

\author{
Elements to the Debate Around Rural Tourism's Concept
}

Luciano Zanetti Pessôa Candiotto ${ }^{1}$

\section{Resumo}

O crescimento do interesse turístico pelo rural, aliado à recente expansão da oferta de turismo no espaço rural brasileiro são aspectos que apontam para uma popularização do turismo rural, e de sua divulgação em diversos meios de comunicação. Por conseguinte, o uso do termo turismo rural vem se ampliando, de modo que é comum a utilização aleatória e muitas vezes indevida do conceito. No meio acadêmico também há um debate acerca do conceito de turismo rural. Procurando dar uma contribuição para esse debate, apresentamos aqui, um artigo que aborda os conceitos de turismo no espaço rural, turismo rural, agroturismo, entre outros. Com base na leitura e interpretação de alguns pesquisadores, bem como em pesquisas empíricas sobre o turismo no espaço rural que realizamos, buscamos nos posicionar em relação aos conceitos trabalhados, apresentando uma proposta de definição.

Palavras-chave: conceitos; turismo rural; turismo no espaço rural; agroturismo.

\begin{abstract}
The growth of interest in rural tourism and the recent expansion of rural tourism's supply in Brazil indicate a tendency of popularization of rural tourism and its dissemination in various media. Therefore, the use of rural tourism's concept has been expanding, but it is common to use random and often inappropriate this concept. In university there is a debate about the concept of rural tourism. Looking to give a contribution to this debate, we present here, an article that discusses the concepts of tourism in rural areas, rural tourism, agritourism, etc. Based on the reading and interpretation of some researchers, as well as our empirical researches on tourism in rural, we try to show our position around the concepts and to propose some definition.
\end{abstract}

Keywords: concepts; rural tourism; tourism in rural areas; agritourism.

\section{Introdução}

A ampliação de experiências (empreendimentos, circuitos, roteiros, etc.), e de estudos e pesquisas relacionadas ao turismo no espaço rural é perceptível no Brasil e em vários países, sobretudo a partir da década de 1990. Esse crescimento do turismo no espaço rural está

\footnotetext{
${ }^{1}$ Doutor em Geografia pela UFSC; Membro do GETERR (Grupo de Estudos Territoriais); Professor Adjunto do Colegiado de Geografia da UNIOESTE (Universidade Estadual do Oeste do Paraná), Campus de Francisco Beltrão. E-mail: lucianocandiotto@yahoo.com.br.
} 
intimamente ligado à ampliação da oferte turística no rural, bem como à maior procura da sociedade por atrativos e empreendimentos relacionados à tranqüilidade e "simplicidade" do campo. Permeando esse processo, temos as ações governamentais de apoio e regulamentação do turismo; a perspectiva de segmentação das modalidades turísticas por parte da Organização Mundial do Turismo (OMT), e consequentemente, pelo trade ${ }^{2}$ turístico; bem como o debate por parte de técnicos e pesquisadores sobre a viabilidade e as conseqüências da abertura de propriedades rurais para atividades de turismo, a partir do aproveitamento de atrativos naturais, históricos, culturais e gastronômicos.

Diferente do turismo sol e praia, que se constituiu na modalidade mais disseminada de turismo, responsável pela urbanização de praias, grande aglomeração de pessoas e, conseqüentemente, diversos impactos socioespaciais, o turismo no espaço rural costuma ter como principal característica uma oferta de equipamentos e de serviços mais simplificada, além de uma demanda menos concentrada e com motivações distintas dos turistas das áreas litorâneas.

Apesar de ter um crescimento concentrado na Europa e nos Estados Unidos a partir da década de 1960, o turismo ganha força na discussão sobre desenvolvimento rural em vários países no início da década de 1990, período em que cresce o fenômeno da pluriatividade ${ }^{3}$ no espaço rural; a concepção de multifuncionalidade ${ }^{4}$ do agricultor e da agricultura; bem como o interesse dos agentes turísticos e da população urbana pelo rural e pelas ruralidades.

Sabendo da relevância do turismo rural como fenômeno de transformação do espaço geográfico, procuramos discutir os conceitos de turismo no espaço rural, turismo rural e agroturismo. Com base na leitura e interpretação de um referencial bibliográfico escrito por autores europeus e brasileiros, bem como em pesquisas empíricas que realizamos sobre o turismo no espaço rural, procuramos nos posicionar em relação aos conceitos trabalhados.

\footnotetext{
${ }^{2}$ Conjunto de empresas vinculadas ao turismo (agentes, operadoras, hotéis e redes hoteleiras, transportadoras, prestadoras de serviços turísticos, etc.).

${ }^{3}$ Maiores detalhes sobre o conceito de pluriatividade em Candiotto (2007b).

${ }^{4}$ Maiores detalhes sobre o conceito de multifuncionalidade em Candiotto (2009).
} 


\section{Elementos Históricos do Turismo no Espaço Rural}

O crescimento global da oferta turística vem intensificando a diversificação das modalidades turísticas, chamada de segmentação, e, conseqüentemente, a busca/criação de novas destinações e de novos produtos turísticos nas últimas décadas.

Como conseqüência da saturação de destinações turísticas "convencionais" (modelo sol e praia), da segmentação dos setores do mercado com o regime de acumulação flexível do capital, e das intencionalidades economicistas e expansionistas do trade turístico, a partir da década de 1990, o turismo passa a ser ideologicamente polarizado entre turismo convencional/de massa e turismo alternativo/sustentável.

Entre as "modalidades" turísticas consideradas alternativas, destacam-se o ecoturismo e o turismo rural, pois ambos pressupõem, teoricamente, que haja uma valorização dos espaços "naturais" e ruralizados (material e simbolicamente). Essa valorização conduziria a um aproveitamento dos recursos naturais, dos objetos técnicos já instalados, e do saber-fazer local. Além disso, o turismo rural tenderia a ser um turismo mais simples, individualizado, de base local, e, portanto, não levaria a grandes mudanças na configuração da paisagem rural.

A recente popularização mundial da prática do turismo rural e dos estudos e pesquisas sobre tal modalidade, está intimamente ligada ao período pós Segunda Guerra Mundial. Ao sintetizar a evolução histórica do Turismo no Espaço Rural de alguns países europeus, Tulik (2003) destaca ações ocorridas a partir do final da década de 1940 e início de 1950.

Em virtude do desenvolvimento econômico pautado na industrialização e das conquistas trabalhistas nos países europeus - como as férias, redução da jornada de trabalho e décimo terceiro salário - ambos ocorridos a partir do fim da Segunda Guerra Mundial, o turismo rural se expande na Europa, passando a ser uma atividade economicamente promissora e incentivada em países como França, Espanha e Itália.

Além dos incentivos públicos para a expansão do turismo como setor econômico estratégico e da organização do trade turístico para viabilizar o turismo rural, o interesse dos citadinos pelo espaço rural, seja para visitas esporádicas ou para moradia, contribuiu para a afirmação do turismo rural, e inseriu novas relações econômicas e sociais no rural. Como aponta Verbole (2002), o aumento da demanda de turismo rural na Europa, devido ao interesse de cidadãos urbanos pelo meio rural, também contribuiu para o incremento da atividade. 
Esse processo de retorno ao campo é denominado neo-ruralismo, iniciado na década de 1970 na França e em outros países europeus. Segundo Giuliani (1990), o neo-ruralismo expressa a idéia de que uma série de valores típicos do velho mundo rural passa por um revigoramento e começa a ganhar a adesão de pessoas da cidade.

Presvelou (2000) lembra que as visitas ao campo já eram comuns, sobretudo para rever parentes e amigos e para o descanso. Todavia, a novidade no interesse pelo rural encontra-se no deslocamento de pessoas na qualidade de turista para o espaço rural.

Durante a década de 1980, há um incremento do turismo no espaço rural europeu, que passa a ser visto como alternativa de renda em função de problemas estruturais nas propriedades rurais, como os baixos preços dos produtos agrários e a redução do protecionismo (TULIK, 2003).

Para Baidal (2000), as possibilidades do turismo rural/natural constituem um aparato para reativação de áreas industriais com problemas, dinamização de áreas rurais atrasadas e diversificação da estrutura econômica regional. Considerando essa realidade de preocupação com o futuro do espaço rural aliada ao interesse pela expansão do turismo rural, a Europa começa a incentivar o turismo no meio rural a partir de políticas públicas da União Européia na década de 1990.

Destacam-se, nesse contexto, as iniciativas LEADER (Ligação Entre Ações de Desenvolvimento da Economia Rural) I, desenvolvida entre 1991 e 1994, LEADER II (19951999), e LEADER+ (2000-2006), lançadas pela Comissão Européia e coordenadas pela Direção Geral de Agricultura.

A partir da formulação do documento O futuro do mundo rural, que " [...] sublinhava a necessidade de experimentar novas abordagens de desenvolvimento e de envolver as comunidades rurais na procura de soluções adequadas” (COMISSÃO EUROPÉIA, 2001, p.8), surgiram as iniciativas LEADER, com o objetivo de promover a transição "[...] de uma lógica de crescimento para uma lógica de desenvolvimento local sustentável, tendo em conta a dimensão ambiental, econômica, social e cultural dos territórios rurais.” (p. 6).

A Comissão Européia (2001, p. 11) ainda informa que visa valorizar " [...] a diversidade dos territórios e das paisagens, a riqueza das identidades locais e a qualidade de um ambiente 
preservado. Neste contexto, a iniciativa LEADER representa um instrumento extraordinário para experimentar as novas possibilidades que se deparam ao meio rural."

Procurando diversificar as economias rurais, a União Européia passa a direcionar recursos para atividades agrícolas e não agrícolas em seu espaço rural. Desta forma, aspectos como a ênfase nas múltiplas funções do espaço rural (produção agropecuária e agroindustrial; segurança alimentar; conservação ambiental, paisagística e cultural; manutenção do tecido social rural); o enfoque multidisciplinar do território para além do setorial (agrícola/rural) que valoriza o uso integrado dos recursos e a diversificação das economias locais; e, a participação da população no planejamento e gestão de base local, são elementos que passam a fundamentar as políticas públicas de desenvolvimento rural na Europa, a partir da década de 1990.

Como conseqüência da implantação das iniciativas LEADER, houve uma diversificação econômica do espaço rural, diversificação que, por sua vez, trouxe consigo um interesse no turismo como uma ferramenta para revitalizar o interior e as comunidades rurais, contribuindo para o desenvolvimento do turismo rural europeu (Verbole, 2002). Baidal (2000) e Presvelou (2000) também ressaltam a importância do LEADER para a promoção e o crescimento do turismo no espaço rural europeu.

A partir da experiência européia da década de 1990 em incentivar o turismo como uma atividade econômica viável para o meio rural, que valoriza o ambiente e a cultura local, o turismo no espaço rural passou a ser considerado uma alternativa de emprego, renda e de desenvolvimento para o rural em todo o mundo ${ }^{5}$. No Brasil, o interesse pela expansão do turismo rural por parte do poder público também vem crescendo significativamente a partir da década de 1990, assim como os estabelecimentos rurais que passam a ofertar algum produto turístico no espaço rural.

Além das dificuldades econômicas dos agricultores e da agricultura em todo o mundo, o apelo ambiental de usos menos degradadores dos recursos naturais e do desenvolvimento sustentável, popularizado no início da década de 1990, contribuíram para a consolidação da ideologia do turismo rural (do ecoturismo e de outras modalidades) como atividades

\footnotetext{
${ }^{5}$ Em interioranos espaços rurais tradicionais, "o turismo passa a ser representado como potencial de desenvolvimento econômico regional. Assim, de produto do desenvolvimento ele passa a ser seu possivel produtor" (BENEVIDES, 2002, p. 105).
} 
potencialmente promotoras do desenvolvimento sustentável. O interesse da sociedade urbana pelo ambiente e pela cultura rural também se apresenta como um dos grandes argumentos para o crescimento do turismo rural, e, conseqüentemente, para a revitalização do espaço rural.

Contudo, quando se fala em turismo rural ficam algumas dúvidas e questionamentos do que vem a ser o turismo rural e quais as atividades representativas dessa modalidade turística. $\mathrm{Na}$ tentativa de apresentar algumas considerações sobre o debate conceitual em torno do turismo rural, bem como nossa posição frente esse debate, discutimos a seguir os conceitos de turismo no espaço rural, turismo rural e agroturismo.

\section{A Questão Conceitual do Turismo Rural}

Em primeiro lugar, para discorrer sobre o turismo rural, não podemos ignorar toda a complexidade que envolve o conceito de rural e sua delimitação espacial, tão dificultada em virtude da expansão espacial dos processos de urbanização e de tecnicização do espaço geográfico. Sabendo da dificuldade em delimitar o que é urbano e o que é rural, preferimos utilizar os conceitos de ruralidades e urbanidades (Candiotto, 2008), tanto para objetos quanto para ações característicos do urbano e do rural. No entanto, para esse debate sobre a questão conceitual relativa ao turismo rural, preferimos manter o uso do conceito de espaço rural, com o intuito de diferenciar o turismo no espaço rural do turismo rural.

Devido à forte influência estrangeira na literatura sobre turismo rural, muitos conceitos são importados sem maiores reflexões e adaptações à realidade brasileira. Como afirma Rodrigues (2000), a imprecisão de conceitos sobre turismo rural no Brasil está vinculada à tentativa de classificações baseadas em parâmetros europeus, haja vista que a origem do turismo rural é européia. Apesar desses problemas conceituais, acreditamos que já existem estudos que buscam estabelecer uma diferenciação das atividades de turismo realizadas no espaço rural no Brasil, sobretudo no que tange aos conceitos de turismo no espaço/meio rural, turismo rural e agroturismo.

A tecnicização do rural vem modificando a dinâmica do espaço rural, principalmente nos países centrais do capitalismo. Esse fato contribui para a expansão do turismo no espaço rural, pois, para haver turismo, é preciso ter infra-estrutura e equipamentos. De forma contraditória, 
porém, o principal elemento motivador do deslocamento ao meio rural se encontra na busca de paisagens e manifestações culturais que, seja na materialidade ou no plano simbólico, se contrapõem ao espaço urbano.

De forma geral, a literatura européia trata qualquer modalidade de turismo realizada no espaço rural como turismo rural. Verbole (2002), Baidal (2000), além dos documentos oficiais da União Européia, não estabelecem tal distinção. Silveira (2001) aponta os três aspectos que definem o turismo rural na Comunidade Européia: o turismo rural é um conceito amplo que engloba não apenas o gozo das férias em fazendas, mas qualquer outra atividade turística que ocorre no campo; o turismo rural recobre, igualmente, toda atividade turística no interior do país; o turismo rural é um conceito que abarca toda a atividade turística endógena suportada pelo ambiente humano e natural.

Apesar de o conceito de turismo rural na Europa abranger qualquer prática turística no espaço rural, autores europeus como $\mathrm{Vaz}^{6}$, $\mathrm{Zarga}^{7}$ e Cals; Capellà; Vaqué estabelecem uma diferenciação entre o turismo rural e o turismo no espaço rural. Cals; Capellà; Vaqué (1995 apud Silva; Vilarino; Dale, 2000) entendem por turismo no meio rural ou turismo em áreas rurais a totalidade dos movimentos turísticos que se desenvolvem no meio rural. Por conseguinte, o Turismo Rural seria restrito às atividades que se identificam com as especificidades da vida rural, seu hábitat, sua economia, sua cultura. Os autores também atentam para o fato de muitas atividades que se apresentam como produtos turísticos do meio rural utilizarem o meio rural apenas como base física.

No contexto brasileiro, Bricalli (2005, p. 41) afirma que "todos os empreendimentos que proporcionem lazer, recreação, descanso ou qualquer outra atividade ligada ao turismo, desde que estejam localizados em áreas rurais, podem ser classificados como turismo no

\footnotetext{
${ }^{6}$ Vaz (1999 apud Silveira, 2001) também vê o turismo rural como algo específico do modo de vida rural, classificando-o como o conjunto de atividades que compõem a vida no campo, envolvendo a experiência do dia-a-dia nas fazendas, o convívio com camponeses, a montaria de cavalos, as plantações, as pastagens, o sabor dos alimentos comidos diretamente da fonte.

${ }^{7}$ Zarga (2001 apud Bricalli, 2005, p. 43) afirma que o turismo rural é "uma atividade que se realiza no mundo rural, composta por uma oferta integrada de ócio dirigida a pessoas interessadas pelo entorno autóctone, pelas atividades rurais e que tenham uma inter-relação com a sociedade local."
} 
espaço rural ", , de modo que o turismo no espaço/meio rural abrange diversas modalidades turísticas.

Segundo Campanhola; Silva (2000, p. 147),

O turismo no meio rural consiste em atividades de lazer realizadas no meio rural e abrange várias modalidades definidas com base em seus elementos de oferta: turismo rural, turismo ecológico ou ecoturismo, turismo de aventura, turismo cultural, turismo de negócios, turismo jovem, turismo social, turismo de saúde e turismo esportivo.

Quando se fala em turismo no meio rural, estão incluídas, portanto, todas as modalidades turísticas praticadas nesse espaço, independentemente da motivação e das atividades envolvidas. Assim como o termo turismo no meio rural, outros autores preferem utilizar o termo turismo no espaço rural ou turismo em áreas rurais, expressões que, em nossa opinião, são equivalentes ${ }^{9}$. O importante nesse debate é que quando se fala em turismo no espaço rural, o componente espacial é preponderante em relação às atividades desenvolvidas, de modo que qualquer atividade turística desenvolvida em um espaço que não seja urbano faz parte do turismo no espaço rural, mas não necessariamente corresponda a uma atividade de turismo rural.

No que tange ao conceito de turismo rural, concordamos com Silva; Almeida (2002) quando estes percebem o turismo rural como uma modalidade mais restrita que o turismo no espaço rural, pois estaria reservado apenas para os casos em que as atividades rurais tradicionais (agricultura, extrativismo e pesca) desempenham algum papel na visita. Tulik (2003) reforça essa idéia, ao colocar que o turismo no espaço rural consiste em qualquer manifestação do turismo nesse meio, enquanto o turismo rural deve estar relacionado ao meio e à produção rural.

Beni (2002, p. 31) conceitua o turismo rural como o "deslocamento de pessoas para espaços rurais, em roteiros programados ou espontâneos, com ou sem pernoite, para fruição dos cenários e instalações rurícolas". O pesquisador brasileiro aplica o mesmo conceito de

\footnotetext{
${ }^{8}$ Os hotéis-fazenda, spas, ecolodges seriam exemplos de empreendimentos turísticos no espaço rural que não apresentam atrativos e equipamentos característicos do rural.

${ }^{9}$ Bricalli (2005) também adota o turismo no meio rural e o turismo em áreas rurais como sinônimos.
} 
turismo ao rural, porém destaca a paisagem e os equipamentos rurais como principais motivadores das viagens.

Rubelo; Luchiari (2005) também apresentam um conceito de turismo rural próprio e bastante abrangente, entendendo-o como:

[...] a somatória de possibilidades que permite ao turista conhecer as práticas sociais das famílias rurais, a cultura rural, o contato com as atividades do campo, com a natureza, com a herança material, expressa ainda nos objetos utilizados para desenvolver as atividades de produção agrícola, e o saber local. (p. 214).

Novaes (2004) apresenta a definição de turismo rural da Organização Mundial do Turismo (OMT), que também destaca o turismo como atividade complementar e integrada à agropecuária.

O Turismo Rural refere-se a lugares em funcionamento (fazendas ou plantações) que complementam seus rendimentos com algumas atividades turísticas, oferecendo geralmente alojamento, refeições e oportunidades de adquirir conhecimentos sobre as atividades agrícolas. (p. 5)

Desta forma, a considerar os autores citados acima, o turismo rural está necessariamente vinculado às características do meio rural (produção agrícola e/ou pecuária, paisagens rurais com vegetação nativa e secundária, arquitetura rural, o contato direto com o modo de vida dos habitantes do campo e com os animais, a culinária da "roça", entre outras). Por conseguinte, os empreendimentos que nada têm a ver com a prática e o conteúdo rural, mas que estão inseridos no espaço rural, fazem parte do turismo no espaço/meio/área rural e não do turismo rural.

Considerando o amplo debate sobre a conceituação do turismo rural, a EMBRATUR (Empresa Brasileira de Turismo) também teve dificuldades em estabelecer um marco conceitual oficial para o turismo rural brasileiro. Tulik (2003) afirma que, em 1994, a EMBRATUR adotou o turismo rural como um conceito múltiplo, e de certa forma confuso, pois abrangeria o turismo diferente, de interior, doméstico, integrado, endógeno, alternativo, 
agroturismo e turismo verde ${ }^{10}$. O principal objetivo do turismo rural no Brasil seria gerar emprego e renda com vistas ao desenvolvimento local.

Outro conceito apresentado pela EMBRATUR em 1998 entendia o turismo rural como o "conjunto de atividades turísticas desenvolvidas no meio rural, comprometido com a produção agropecuária, agregando valor a produtos e serviços, resgatando e promovendo o patrimônio cultural e natural da comunidade”. (BRASIL, 1998, p. 14). O turismo rural seria, portanto, uma atividade complementar às atividades agrícolas e/ou pecuárias, que estaria, simplesmente por sua própria existência, contribuindo para a dinamização econômica do espaço rural, e para a valorização da cultura e da natureza ${ }^{11}$.

Cabe ressaltar a diferença entre o conceito de 1994, extremamente amplo, vago e confuso, para o de 1998, que passa relacionar o turismo rural com a produção agropecuária. Assim, enquanto em 1994 o turismo rural abrangeria outras modalidades turísticas ofertadas no espaço rural na visão do governo federal, em 1998 há um considerável avanço conceitual, pois o turismo rural passa a estar restrito a atividades tradicionais do rural, sobretudo à agricultura e pecuária.

Todavia Tulik (2003, p. 74) afirma que, em 2002, houve uma mudança no conceito de turismo rural da EMBRATUR, que passou a ser considerado "um segmento do turismo que proporciona conhecer, vivenciar e usufruir as práticas sociais, econômicas e culturais próprias do meio rural de cada região de forma sustentável”. Mesmo com a mudança conceitual, o turismo rural se manteve vinculado às práticas rurais, e não somente ao espaço rural, mostrando que a existência ou manutenção das atividades agropecuárias são elementos fundamentais para caracterizar o turismo rural. Ademais, este conceito passa a fazer referência à sustentabilidade no turismo, demonstrando a força da ideologia do turismo sustentável e, conseqüentemente, do desenvolvimento sustentável, cada vez mais utilizada na retórica de governos, empresas, políticos, pesquisadores e outros sujeitos sociais.

\footnotetext{
${ }^{10}$ Não estabeleceremos aqui uma discussão sobre essas modalidades turísticas, porém temos questionamentos em relação ao que cada uma significa especificamente, sobretudo turismo diferente, integrado e verde. Enfocaremos apenas o conceito de agroturismo.

${ }^{11}$ Questionamos essa premissa de que o turismo rural certamente trará benefícios às comunidades receptoras, e entendemos que essa afirmação somente pode ocorrer a partir de pesquisas que apreendam as implicações socioespaciais de experiências empíricas de turismo rural.
} 
Em 2004, o conceito de Turismo no Espaço Rural também passa a ser adotado pelo governo federal. Em documento do Programa Nacional de Turismo Rural na Agricultura Familiar, o turismo no espaço rural abrangeria todos "os equipamentos localizados na área rural que desenvolvem atividades de lazer, recreação, esportivas, de eventos, não apresentando, necessariamente, vínculo com a produção agropecuária e a cultura rural”. (BRASIL, 2004, p. 7).

Portanto, as alterações no conceito de turismo rural e a incorporação do conceito de turismo no espaço rural por parte do governo federal demonstram alguma evolução conceitual, sobretudo pelo fato de reconhecer a diferença entre o turismo no espaço rural e o turismo rural.

Além de todo o debate em torno dos conceitos de turismo no espaço rural e turismo rural, o conceito de agroturismo também se apresenta como fundamental para a diferenciação das atividades turísticas realizadas no meio rural.

De forma geral, entendemos que o agroturismo apresenta todos os atributos do turismo rural, sobretudo pelo fato de ser uma atividade realizada no espaço rural, e ter como principais atrativos as atividades agropecuárias, os produtos paraagrícolas e o modo de vida rural. Ocorre, porém, que o diferencial do agroturismo em relação ao turismo rural diz respeito à participação direta e/ou indireta do turista em atividades comuns dos agricultores, como plantio, colheita, ordenha, entre outras. Nesse sentido, toda a oferta de agroturismo poderia ser classificada como turismo rural, porém nem toda a oferta de turismo rural pressupõe a existência do agroturismo.

Beni (2002, p. 32) apresenta o seguinte conceito de agroturismo: “[...] deslocamento de pessoas para espaços rurais, em roteiros programados ou espontâneos, com ou sem pernoite, para fruição dos cenários e observação, vivência e participação em atividades agropastoris." Comparando os conceitos atribuídos por Beni de turismo rural e de agroturismo, a única inserção feita para o agroturismo diz respeito à vivência e participação dos turistas em atividades agropastoris.

Beni (2002) afirma, contudo, que dois aspectos distinguem o agroturismo do turismo rural:

1. A produção agropastoril é a maior fonte de renda da propriedade de agroturismo, de modo que o turismo gera uma receita complementar; 
2. As próprias atividades agropastoris constituem o principal diferencial turístico, de modo que o turista pode participar ou não da rotina da propriedade.

No que tange à idéia do turismo como fonte de renda complementar às atividades agrícolas, os conceitos de turismo rural da OMT e da EMBRATUR também apontam para esse princípio. Apesar de ambas as instituições não apresentarem um conceito específico de agroturismo - dando a impressão de entenderem este como sinônimo de turismo rural - elas consideram que a complementaridade com as atividades agropecuárias deva fazer parte do

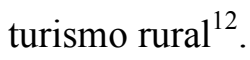

Se partirmos do princípio de que, no turismo rural, para se diferenciar do turismo no espaço rural, deva haver uma interação com as atividades e os estilos de vida característicos do rural $^{13}$, isto é, com elementos de ruralidades, pressupomos também que a manutenção de atividades agrícolas ou pecuárias seja fundamental para a própria existência do turismo rural.

Mesmo em empreendimentos turísticos rurais altamente tecnicizados, como um haras, uma fazenda experimental ou um pesque-pague, algum tipo de atividade agropecuária é mantido. Assim, podemos afirmar que a complementaridade com atividades agropecuárias deve fazer parte de qualquer oferta de turismo rural, mas tais atividades podem ser ou não os principais atrativos do turismo rural. Ademais, diversos empreendimentos possuem cultivares e animais para servir ao turismo (seja como atrativo ou como alimento), mas podem não ter as atividades agropecuárias como a principal fonte de renda.

Já no agroturismo, as atividades agropecuárias, além de antecederem o turismo, são os grandes atrativos turísticos. Para Bricalli (2005), o agroturismo está intimamente relacionado às atividades agropecuárias da propriedade, e aquelas que ofertam essa modalidade costumam ser pequenas (até 50 ha) e de estrutura familiar. Não obstante, concordamos com Beni (2002), que no agroturismo deva haver complementaridade com as atividades agropecuárias, pois, além de estas se constituírem nos principais atrativos do agroturismo (seja através do contato com plantações e animais, da oferta de refeições, ou da compra e consumo de produtos alimentares in natura ou processados), geralmente garantem a sobrevivência dos agricultores e de suas famílias, principalmente nos períodos de pouca visitação.

\footnotetext{
12 Todavia, entendemos que essa preocupação dos órgãos oficiais de turismo está vinculada principalmente ao interesse em manter as atividades características do rural como mercadorias para o turismo rural.

${ }^{13}$ Conforme indicam todos os autores usados acima para conceituar o turismo rural.
} 
Desta forma, podemos afirmar que, assim como o turismo rural faz parte de algo mais amplo, que é o turismo no espaço rural, o agroturismo se constitui em uma submodalidade do turismo rural. O esquema a seguir (Figura 1), busca ilustrar essa questão.

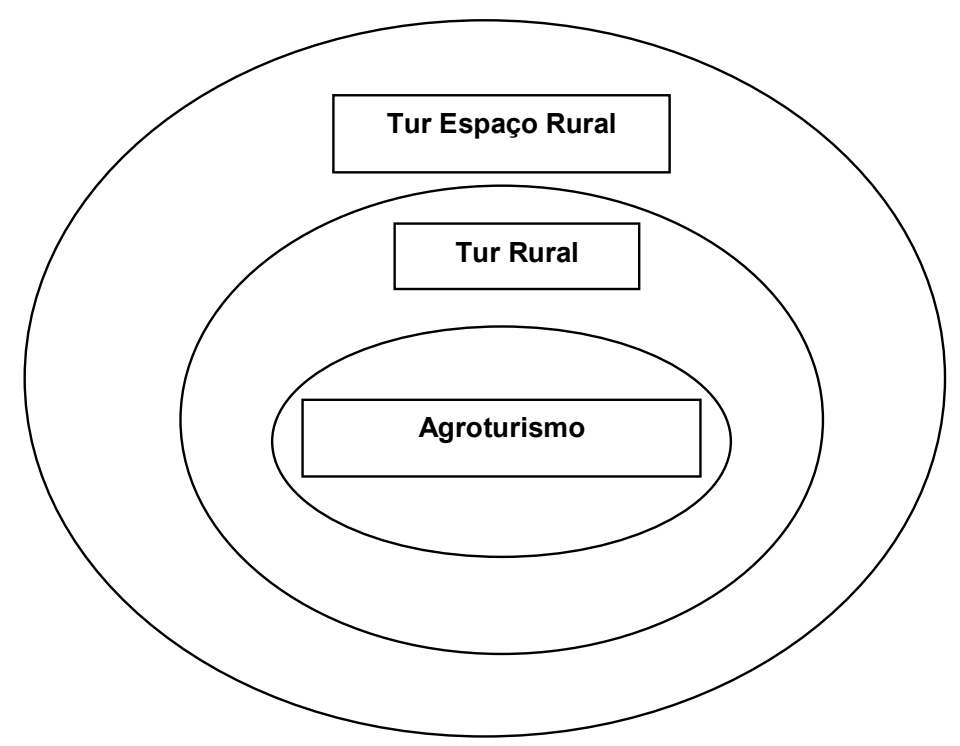

Figura 1 - Hierarquia do Turismo no Espaço Rural

Fonte: Organizado por CANDIOTTO, L. Z. P. (2007a)

Silva; Vilarino; Dale (2000) utilizam o conceito de agroturismo como sinônimo de turismo rural, fato que consideramos questionável, pois entendemos que o agroturismo tem mais especificidades que o turismo rural. Os autores consideram que o agroturismo seria uma estratégia de diversificação produtiva das propriedades rurais, através de atividades internas à propriedade e ao modo de vida rural, que geram ocupações complementares às atividades agrícolas. Como exemplos, citam a fazenda-hotel, o pesque-pague, a fazenda de caça, a pousada, o restaurante típico, as vendas diretas do produtor, o artesanato, a valorização da paisagem, e a industrialização caseira.

Novaes (2004) busca estabelecer um debate em torno da conceituação sobre o turismo rural, porém não avança muito, pois diferencia turismo no espaço rural de turismo rural, mas, assim como Silva; Vilarino; Dale (2000), vê o turismo rural e o agroturismo como sinônimos. 
Verbole (2002) ressalta o envolvimento dos proprietários dos empreendimentos em atividades agropecuárias, mas não vincula o agroturismo à participação do turista em tais atividades. Para o autor, os empreendedores do agroturismo devem ser agricultores ${ }^{14}$. Como Verbole é europeu e chama de turismo rural qualquer atividade turística realizada no espaço rural, seu conceito de agroturismo parece ser similar ao conceito de turismo rural utilizado no Brasil e oficializado pela EMBRATUR, pois o autor destaca a existência de alguma atividade agropecuária como elemento definidor do agroturismo.

Entendemos que todos os empreendimentos de agroturismo devem possuir atividades agropecuárias, mas o principal elemento caracterizador desta modalidade estaria no uso das atividades agropecuárias e do estilo de vida do agricultor como os principais atrativos, e na participação direta ou indireta dos turistas em tais atividades.

Apesar de também usar o termo turismo rural como sinônimo de turismo no espaço rural, Baidal (2000) apresenta uma definição de agroturismo distinta da de Verbole (2002), pois considera a participação do turista em atividades agropecuárias, e acrescenta a oferta de pernoite na propriedade rural como uma exigência básica para se afirmar a existência do agroturismo $^{15}$. Para Baidal (2000), o agroturismo:

[...] se fundamenta no desfrute de experiências ligadas a uma exploração agrícola ou pecuária. É o próprio agricultor quem aloja o turista (em sua própria residência ou em edificações já existentes adaptadas para pernoites), e este participa das tarefas agrícolas ou pecuárias, ativamente ou como expectador. (p. 76)

Ao pesquisar uma experiência de agroturismo no Estado do Espírito Santo, Portuguez (1999) definiu o mesmo como:

[...] a modalidade de turismo em espaço rural praticada dentro das propriedades, de modo que o turista e/ou excursionista entra, mesmo que por curto período de

\footnotetext{
14 “O agroturismo se refere a todas as formas de turismo diretamente relacionadas ao ambiente agrário, produtos ou habitações agrárias. Os provedores desse produto turístico estão diretamente engajados na agricultura." (VERBOLE, 2002, p. 121).

15 Como a pernoite é um dos principais elementos que diferenciam o turismo do lazer, a oferta de pernoite pressupõe que o empreendimento oferece turismo. Já aqueles empreendimentos que não oferecem pernoite não poderiam ser considerados empreendimentos turísticos, mas, sim, empreendimentos de lazer. Ao considerar as visitas sem pernoite como turismo, a conceituação de turismo rural e de agroturismo proposta por Beni (2002), é passível, portanto, de questionamentos.
} 
tempo, em contato com a atmosfera da vida na fazenda, integrando-se de alguma forma aos hábitos locais. (p. 77).

Portuguez não enfatiza a participação direta ou indireta do turista em alguma atividade agropecuária como um elemento definidor do agroturismo, falando apenas de contato e integração com os hábitos locais. Dependendo do tipo de estabelecimento rural, seja uma pequena propriedade familiar, uma chácara de lazer, uma propriedade com culturas integradas ou até uma fazenda de monocultura, a atmosfera da vida e os hábitos locais serão bem diferentes, de modo que fica difícil afirmar que todos esses tipos de estabelecimento oferecem o agroturismo. Assim, entendemos que Portuguez apresenta uma proposta conceitual de agroturismo limitada, que seria mais próxima do conceito de turismo rural.

Campanhola; Silva (2000) também apontam que o agroturismo se refere às atividades turísticas que ocorrem no interior das propriedades que desenvolvem atividades agropecuárias. Na tentativa de estabelecer um conceito adaptado à realidade brasileira, os autores vêem o agroturismo relacionado à:

Atividades internas à propriedade, que geram ocupações complementares do cotidiano da propriedade, em menor ou maior intensidade, sendo parte de um processo de agregação de serviços aos produtos agrícolas e bens não materiais existentes nas propriedades rurais (paisagem, ar puro, etc.), a partir do "tempolivre" das famílias agrícolas, com eventuais contratações de mão-de-obra externa. (CAMPANHOLA; SILVA, 2000, p. 148).

Apesar de destacarem a complementaridade do turismo em relação às atividades agropecuárias, os autores também não apontam como elemento definidor, a participação dos turistas em tais atividades. Assim, não percebemos uma clara distinção em relação ao turismo rural. Todavia, a ênfase dada às famílias agrícolas como receptoras do agroturismo abre uma nova frente de debate, vinculada à viabilidade e às conseqüências da inserção de agricultores familiares na oferta do turismo rural e, mais especificamente, do agroturismo ${ }^{16}$.

Tulik (2003) aponta que toda a referência teórica do agroturismo também é européia, porém, como vimos nas definições de Verbole (2002) e Baidal (2000), existem diferenças significativas nas conceituações em torno do agroturismo na Europa. Com base na literatura

\footnotetext{
${ }^{16}$ Procuramos discutir esse assunto em Candiotto (2007a).
} 
européia, com destaque para o trabalho de Martín Gil de 1997, Tulik (2003) apresenta os princípios que devem nortear o agroturismo:

- atividade agrícola e/ou pecuária na propriedade;

- turismo como atividade complementar da renda e das outras atividades agrícolas;

- organização e gestão familiar, sendo obrigatória a presença do proprietário;

- alojamento em propriedade rural integrado à moradia do proprietário, ou em apartamentos individuais remodelados ou construídos para este fim;

- alimentação baseada na cozinha tradicional do lugar e elaborada com produtos locais;

- eventual oferecimento de atividades alternativas de lazer e recreação no entorno da propriedade;

- participação do turista nas atividades rotineiras (cultivo e colheita, cuidados com o gado, preparação de alimentos tradicionais) ou, pelo menos, possibilidade de observação;

- contato direto com o meio rural e a população residente;

- caracterizado como um modelo difuso, em pequena escala, não congestionado, com aproveitamento máximo dos recursos existentes.

Consideramos que essa sistematização dos princípios do agroturismo feita por Tulik (2003) é extremamente pertinente para se pensar a definição de agroturismo no Brasil. Apesar de não concordarmos com a simples importação de conceitos elaborados em realidades diferentes da brasileira, os princípios apresentados mostram algumas peculiaridades do agroturismo, sobretudo no que tange à participação do turista nas atividades da propriedade, o aproveitamento da culinária local, e o contato entre turistas e autóctones.

Bricalli (2005) procura avançar nas definições de turismo rural, sugerindo e aplicando três novas categorias dentro do turismo rural: o turismo rural familiar, turismo rural empresarial e turismo rural misto. Na categoria familiar ideal,

[...] a residência do empreendedor é no próprio empreendimento, a mão-de-obra utilizada nas tarefas é familiar, o estilo das edificações apresenta características rurais, os atrativos turísticos são locais e as atividades agrícolas se fazem presentes. (p. 66). 
Já na categoria empresarial ideal,

[...] a residência do empreendedor é fora do empreendimento, a mão-de-obra utilizada nas tarefas é contratada, o estilo das edificações apresenta características urbanas, os atrativos turísticos são artificiais e as atividades agrícolas não existem. (p. 66).

As situações descritas por Bricalli (2005) como ideais estão situadas em extremos, podendo, na prática, ocorrer situações intermediárias. Para os empreendimentos que apresentaram características dos dois modelos, o autor usou, em seu estudo empírico, a categoria turismo rural misto ${ }^{17}$.

Apesar de considerarmos pertinente a proposta de Bricalli (2005), acreditamos na existência de uma heterogeneidade muito maior entre os empreendimentos de turismo rural. Existem empreendimentos que não se encaixam totalmente nas categorias familiar e empresarial ideal, mas que podem ser considerados familiares e/ou empresariais. Da mesma forma, o autor atribui à categoria misto uma diversidade de empreendimentos que podem ter características bem diferentes. Um empreendimento pode ser classificado como familiar ou empresarial sem necessariamente apresentar todas as características apontadas pelo autor.

Em nossa opinião, o conceito de agroturismo permite incorporar grande parte dos agricultores familiares envolvidos com o turismo, pois, além da existência de atividades agropecuárias, os agricultores familiares costumam ter seus principais atrativos vinculados a tais atividades, seja por meio da observação e da participação em atividades agrícolas e pecuárias, da comercialização de produtos in natura e transformados, do uso de animais para atividades de lazer (pesca, passeios a cavalo, charrete, carro de boi), e do modo de vida rural tradicional, onde se planta e se vive da "terra". Registre-se, no entanto, que também existem agricultores familiares que abrem suas propriedades por possuírem algum atrativo natural (cachoeiras, rios, escarpas, cavernas, matas), e que não aproveitam a demanda existente para valorizar suas atividades agropecuárias cotidianas. Estes agricultores não estariam ofertando agroturismo, mas o ecoturismo ou o turismo eco-rural, ambos inseridos no turismo no espaço rural.

\footnotetext{
${ }^{17}$ Ao aplicar essas tipologias em sete empreendimentos de turismo rural no município de Alfredo Chaves - ES, Bricalli (2005) verificou que quatro caracterizam predominantemente o turismo rural familiar, dois são empreendimentos de turismo rural empresarial e um foi classificado como misto, pois não possui atividade agrícola, o proprietário não reside no local e há contratação de mão-de-obra.
} 
Tessari (2001) elenca os seguintes objetivos do agroturismo: - promover a melhoria da vida da população rural, complementando a renda; - reduzir o fluxo e os efeitos do êxodo rural; valorizar o potencial agrícola e turístico do campo; - reforçar a filosofia de um turismo que promova a conservação ambiental e a cultura regional.

Os objetivos apontados por Tessari (2001) demonstram que o agroturismo deve ter como maior beneficiária a população rural, sobretudo os agricultores. Não obstante, os projetos e políticas públicas de agroturismo devem ter como foco a melhoria da qualidade de vida do homem do campo, e não o atendimento aos anseios e ao imaginário dos turistas, fortemente influenciados pelo trade e pela mídia.

Ao analisar um estudo do CEPA (Centro de Socioeconomia e Planejamento Agrícola), órgão do Estado de Santa Catarina responsável por um levantamento dos empreendimentos de agroturismo no Estado, Moraes; Leite; Souza (2006) indicam as seguintes características utilizadas para definir o empreendimento agroturístico:

- o agricultor deve desenvolver atividades agropecuárias e residir na propriedade;

- a mão-de-obra familiar ocupada na atividade do turismo deve representar no mínimo $50 \%$ da mão-de-obra total no período de maior demanda turística;

- a renda das atividades agropecuárias deve ser igual ou maior a 20\% da renda líquida anual da unidade familiar.

As características usadas pelo CEPA demonstram que o público-alvo para ofertar o agroturismo é constituído majoritariamente pelos agricultores familiares, aspecto já enfatizado anteriormente. Assim, quando se fala em turismo rural na agricultura familiar, há um destaque para o agroturismo como modalidade mais adequada à realidade dos pequenos agricultores.

No entanto, as características usadas por Moraes; Leite; Souza (2006) não fazem nenhuma referência à necessidade de participação direta ou indireta do turista em atividades agropecuárias tradicionais, fato que acreditamos ser fundamental para caracterizar o agroturismo. Assim, as características que os autores acima utilizam para definir um empreendimento agroturístico, correspondem em nossa opinião, à importantes características para definir os empreendimentos de turismo rural de propriedade e/ou gestão por parte de agricultores familiares, mas não se constituem em características definidoras do agroturismo. 
Além desse debate sobre os conceitos referentes ao turismo rural que procuramos apresentar, é pertinente ressaltar o uso indevido dos termos turismo rural e agroturismo em empreendimentos que não oferecem pernoite. Geralmente há uma preferência de agências, empreendedores, comerciantes e políticos em enfatizar a comercialização de uma oferta de turismo rural e agroturismo, pois isso atrai mais os turistas em potencial. Todavia, a maior parte dos empreendimentos que dizem oferecer o turismo rural e o agroturismo, ao não ofertarem o pernoite, estariam oferecendo apenas o lazer ou o excursionismo, e não propriamente o turismo.

\section{Considerações Finais}

O debate conceitual se faz pertinente para qualquer área do conhecimento, pois através dos conceitos, dialogamos com a realidade e procuramos teorizar os elementos empíricos que pesquisamos. Ao perceber um uso indiscriminado dos conceitos relacionados ao turismo rural, com destaque para o próprio conceito de turismo rural, onde quase toda a oferta de lazer e turismo presente no complexo, heterogêneo e híbrido "espaço rural" é comumente autodenominada como turismo rural, procuramos discorrer e apresentar elementos do debate em torno do conceito de turismo rural.

Ao estabelecermos a diferenciação entre turismo no espaço rural; turismo rural e agroturismo, procuramos nos posicionar frente esse debate, sem, no entanto, ignorar outros conceitos correlatos já utilizados por instituições públicas, privadas e no meio acadêmico, como o de turismo rural na agricultura familiar, turismo comunitário, turismo de base local, entre outros.

Acreditamos que a reflexão acadêmica acerca dos conceitos, e sua correta aplicação no meio acadêmico, entre o trade turístico, na mídia e também na sociedade em geral, tendem a qualificar a oferta e a demanda turística no espaço rural, e a proporcionar condições para o necessário aperfeiçoamento dos conceitos e da aplicação destes nas realidades empíricas estudadas em todo Brasil, pois a abstração teórica e conceitual é fundamental para apreender o real. 


\section{Referências}

BAIDAL, Josep A. I. 2000. Turismo y espacios rurales: conceptos, filosofias y realidades. Estudios territoriales, Buenos Aires, n. 23, p. 59-88, enero-junio.

BENEVIDES, Ireleno P. 2002. O lugar do turismo nas políticas públicas para o desenvolvimento: notas conceituais para uma abordagem geográfica. In: SOUZA, Maria J. (Org.). Políticas públicas e o lugar do turismo. Brasília: UNB; MMA, p. 99-110.

BENI. M. C. 2002. Conceituando turismo rural, agroturismo, turismo ecológico e ecoturismo. In: BARRETTO, Margarita e TAMANINI, Elizabeth. (Org.). Redescobrindo a ecologia no turismo. Caxias do Sul: EDUCS, p. 31-34

BRASIL.2004. Programa Nacional de Turismo Rural na Agricultura Familiar (PNTRAF). Ministério do Desenvolvimento Agrário, (CD-ROM).

BRASIL. 2003. Diretrizes para o Desenvolvimento do Turismo Rural no Brasil. Ministério do Turismo/Secretaria de Políticas de Turismo, (documento digital).

BRASIL. 1998. Oficina de planejamento: subsídios ao Plano Nacional de Turismo Rural. Brasília: EMBRATUR.

BRICALLI, Luiz Carlos. 2005. Estudo das tipologias do Turismo Rural-Alfredo Chaves (ES). Santa Maria: Ed. Facos.

CAMPANHOLA, Carlos; SILVA, José G. da. 2000. O turismo como nova fonte de renda para o pequeno agricultor brasileiro. In: ALMEIDA, J. A. e RIEDL, M. (Org.). Turismo rural: ecologia, lazer e desenvolvimento. Bauru, SP: EDUSC, p. 145-179.

CANDIOTTO, Luciano Z. P. 2009. Aspectos históricos e conceituais da multifuncionalidade da agricultura. In: XIX Encontro Nacional de Geografia Agrária, 2009, São Paulo. XIX ENGA Formação e contemporaneidade da diversidade sócio-espacial no campo. Anais.... São Paulo, 2009. (CD-ROM). Disponível em: < http://www.geografia.fflch.usp.br/inferior/laboratorios/agraria/Anais \%20XIXENGA/artigos/Candiotto_LZP.pdf>.

2008. Ruralidades, urbanidades e a tecnicização do rural no contexto do debate cidade campo. Campo e Território, v. 3, n. 5, p. 214-242.

2007a. Turismo rural na agricultura familiar: uma abordagem geográfica do Circuito Italiano de Turismo Rural, município de Colombo - PR. Tese (Doutorado em Geografia). Univ. Federal de Santa Catarina, Florianópolis-SC. 
2007b. Pluriatividade: aspectos históricos e conceituais. Faz Ciência, Francisco Beltrão, v. 9, n. 10, jul-dez. p. 191-208.

COMISSÃO EUROPÉIA. 2001. LEADER, de uma Iniciativa a um Método: guia pedagógico da acção LEADER. Direção Geral de Agricultura, (documento digital). Disponível em: $<\mathrm{http}: / /$ ec.europa.eu/agriculture/rur/leader2/dossier_p/pt/contents.htm $>$.

CRISTÓVÃO, Artur. 2002. Mundo rural: entre as representações (dos urbanos) e os benefícios reais (para os rurais). In: RIEDL, Mario; ALMEIDA, Joaquim A.; VIANA, Andyara L. B. Turismo rural: tendências e sustentabilidade. Santa Cruz do Sul: EDUNISC, p. 81-116.

GIULIANI, Gian. M.1990. Neo-ruralismo: o novo estilo dos velhos modelos. Revista Brasileira de Ciências Sociais, São Paulo, n.14, ano 5, out. p. 59-67.

MORAES, Cléia S.; LEITE, Juliano; SOUZA, Marcelino. 2006. O processo administrativo em empreendimentos de agroturismo em SC. In: CONGRESSO INTERNACIONAL SOBRE TURISMO RURAL E DESENVOLVIMENTO SUSTENTÁVEL, 5, Santa Maria. Anais: ordenação, segmentação e regionalização do turismo em áreas rurais. Santa Maria: FACOS/UFSM, p. 351-360.

NOVAES, Carla A. 2004. Turismo rural e agroturismo diferenciado de turismo em espaço rural: uma proposta. In: CONGRESSO INTERNACIONAL SOBRE TURISMO RURAL E DESENVOLVIMENTO SUSTENTÁVEL, 4, 2004, Joinville. Anais... Joinville: IELUSC, (CD ROM). RUBELO, João e LUCHIARI, Maria T. 2005. O Circuito das Frutas - SP no contexto do turismo rural. CONGRESSO BRASILEIRO DE TURISMO RURAL, 5, 2005, Piracicaba. Anais: Propriedades, comunidades e roteiros do turismo rural. Piracicaba: FEALQ, p. 211-216.

RODRIGUES, Adyr B. 2000. Turismo rural no Brasil: ensaio de uma tipologia. In: ALMEIDA, J. A. e RIEDL, M. (Org.). Turismo rural: ecologia, lazer e desenvolvimento. Bauru: EDUSC, p. 51-68.

PRESVELOU, Clio. 2000. Ações inovadoras em turismo rural. In: ALMEIDA, J. A.; FROELICH, J. M.; RIEDL, M. (Org.). Turismo rural e desenvolvimento sustentável. Campinas, SP: Papirus, p. 143162.

PORTUGUEZ, Anderson P. 1999. Agroturismo e desenvolvimento regional. São Paulo: Hucitec.

SILVA, Maurem F. e ALMEIDA, Joaquim. A. 2002. Turismo rural: família, patrimônio e trabalho. In: RIEDL, Mario; ALMEIDA, Joaquim A.; VIANA, Andyara L. B. (Org.). Turismo rural: tendências e sustentabilidade. Santa Cruz do Sul: EDUNISC, p. 165-203. 
SILVA, José G. da; VILARINHO, Carlyle; DALE, Paul. 2000. Turismo em áreas rurais: suas possibilidades e limitações no Brasil. In: ALMEIDA, J. A.; FROELICH, J. M.; RIEDL, M. (Org.). Turismo rural e desenvolvimento sustentável. Campinas: Papirus, p. 15-62.

SILVEIRA, Marcos T. 2002. Turismo, políticas de ordenamento territorial e desenvolvimento: um foco no estado do Paraná no contexto regional. Tese (Doutorado em Geografia). USP, São Paulo.

SILVEIRA, Marcos T. 2001. Política de turismo: oportunidades ao desenvolvimento local. In: RODRIGUES, Adyr B. (Org.) Turismo rural: práticas e perspectivas. São Paulo: Contexto, p. 133150.

TESSARI, R. O que é agroturismo? 2001. In: PORTUGUEZ, A. P. (Org.). Consumo e espaço: turismo, lazer e outros temas. São Paulo: Roca.

TULIK, Olga. 2003.Turismo Rural. São Paulo: Aleph.

VERBOLE, A. 2002. A busca pelo imaginário rural. In: RIEDL, Mario; ALMEIDA, Joaquim A.; VIANA, Andyara L. B. (Org.). Turismo rural: tendências e sustentabilidade. Santa Cruz do Sul: EDUNISC, p. 117-140.

Recebido em: 03/08/2009 ( $1^{\mathrm{a}}$ versão) $02 / 02 / 2010$ ( $2^{\mathrm{a}}$ versão)

Aprovado: 26/02/2010 